\title{
Jornalismo e transparência pública digital: aliados pela qualidade do debate público
}

\section{Marlise Viegas Brenol}

Universidade de Brasília, Faculdade de Comunicação, Departamento de Jornalismo, Brasília, DF, Brasil ORCID: https://orcid.org/0000-0002-6245-3916

\section{Resumo}

O objetivo deste artigo é situar o jornalismo na democracia digital. Por meio de revisão e discussão bibliográfica, propomos a abordagem da evolução da normatividade da transparência pública digital no Brasil até a aprovação da Lei de Acesso à Informação (LAI) e do uso e apropriação da informação na prática jornalística, à luz das noções de democracia digital e comunicação pública. Como resultado, identificamos um conjunto significativo de estudos que apontam que o jornalismo adotou, em especial, instrumentos de transparência passiva para acessar dados públicos e que essa prática tem se intensificado no país desde a aprovação da LAI.

\section{Palavras-chave}

Jornalismo. Lei de Acesso à Informação (LAI). Transparência pública digital. Democracia digital. Políticas de transparência pública. Acesso à informação pública.

\section{Introdução: o social e o técnico da transparência pública}

Este artigo se associa à ideia de que a transparência pública digital pode ser observada por dois âmbitos: o social e o técnico. Os dois não podem ser dissociados, tendo em vista que o social inclui questões de políticas públicas, determina novas legislações, bem como posicionamentos institucionais de governos e de outros atores atuantes em regimes democráticos. A dimensão técnica da transparência pública está vinculada ao acesso por meios digitais e ao formato do dado aberto para ser apropriado - apto para reúso - pelo âmbito social, dentro do entendimento de democracia digital, ou seja, aspectos da democracia que se configuram como campo no encontro da internet com as políticas públicas de acesso à informação pública, accountability e arquivamento. A questão da 
abertura está diretamente vinculada à digitalização dos dados, etapa anterior ao acesso a informações públicas.

A democracia digital (GOMES, 2007) é um campo de estudo que observa como as políticas públicas e a sociedade são impactadas e impactam ferramentas de participação, deliberação e transparência. A democracia digital associa o governo ou o Estado a softwares de cunho político e social com a finalidade de melhorar o sistema político, ou seja, "se refere ao uso de tecnologias digitais para concretizar avanços do ideário democrático" (SILVA; SAMPAI0; BRAGAT0, 2016, p. 19). Há, na democracia digital, além da transparência de disponibilização e acesso, a dimensão deliberativa e participativa conformando ferramentas de e-government e de governo aberto.

Portanto, a prática do jornalismo que faz uso e apropriação de dados públicos digitais está diretamente vinculada à disponibilização de dados governamentais estimulada por políticas públicas intensificadas a partir de meados dos anos 2000 no Brasil. Este artigo propõe, por meio de revisão bibliográfica qualitativa, discutir o jornalismo na democracia digital. Para tanto, o texto foi assim organizado: (1) a evolução da normatividade da transparência pública digital; (2) como o jornalismo se apropria do acesso à informação na prática; e (3) como o jornalismo é abordado por autores da democracia digital e colabora com o debate em redes de comunicação pública.

\section{A normatividade na transparência}

Os dados públicos digitais (acessíveis e abertos para reúso), garantidos por normas legais e disponibilizados para a sociedade, potencialmente amplificam o conhecimento social sobre o Estado e assim geram mais transparência e controle cidadão sobre a ação de representantes e entes públicos. Os dados digitais podem ser usados para diversos fins, desde iniciativas cívicas, prestação de serviços sociais até propaganda, marketing ou outro. A disponibilização, o acesso, o uso e a apropriação social de dados públicos para controle social foi normatizada a partir do entendimento democrático de que o acesso à informação é considerado um direito fundamental.

O país pioneiro na criação de norma própria para garantia desse direito foi a Suécia, que regulamentou a liberdade de acesso a informações públicas em 1766. Na América Latina, a Colômbia estabeleceu o Código de Organização Política e Municipal em 1888, 
regulamentando o direito dos cidadãos receberem informações dos órgãos governamentais (MENDEL, 2009).

No século XX, as discussões sobre direitos humanos transversais levaram à redação da própria Declaração Universal dos Direitos Humanos, de 1948. No artigo 19 do documento, está expresso que "Todo ser humano tem direito à liberdade de opinião e expressão; este direito inclui a liberdade de, sem interferência, ter opiniões e de procurar, receber e transmitir informações e ideias por quaisquer meios e independentemente de fronteiras" (ORGANIZAÇÃO DAS NAÇÕES UNIDAS, 2009, p. 10). Nos anos seguintes à Declaração Universal dos Direitos Humanos, a Finlândia aprovou sua lei de acesso, em 1951. Os Estados Unidos aprovaram a Lei de Liberdade de Informação, conhecida como FOIA (Freedom of Information Act), em 1966 e a Dinamarca, em 1970 (MENDEL, 2009).

De fato, a maioria dos países só regulamentou o direito à informação pública a partir do final dos anos 1990 e início dos anos 2000. 0 período histórico de ascensão da garantia deste direito leva a dois fatores preponderantes: o contexto político de transição de regime político e o avanço das tecnologias de redes de computadores que culminaria com o acesso à internet, com ampliação das possibilidades de uso e apropriação social de dados digitais. Mendel (2009) acredita que, apesar do contexto político, a tecnologia teve um papel definitivo para a consolidação das leis de acesso à informação, que segundo o autor "melhorou a capacidade do cidadão comum de controlar a corrupção, cobrar dos líderes e de contribuir para processos decisórios" (MENDEL, 2009, p.4). No Brasil, o período de redemocratização do país após o regime militar começou em 1975 e teve como característica uma abertura lenta e gradual. 0 processo compreendeu medidas de ampliação de garantias individuais, coletivas e de imprensa. Mas a aprovação da Constituição brasileira só se concretizou em 1988. No primeiro capítulo da carta constitucional, o dos Direitos e Deveres Individuais e Coletivos, no inciso XXXIII do artigo 5, está a garantia do acesso à informação pública na qual prevê que todo cidadão possui o direito fundamental receber dos órgãos públicos "informações de seu interesse particular, ou de interesse coletivo ou geral, que serão prestadas no prazo da lei, sob pena de responsabilidade, ressalvadas aquelas cujo sigilo seja imprescindível à segurança da sociedade e do Estado." (BRASIL, 1988)

A partir da Constituição de 1988, novas legislações como a Lei de Responsabilidade Fiscal (Lei Complementar no 101), a Lei do Habeas Data (Lei o 9.507) e a Lei de Arquivos (Lei no 8.159) (figura 1) entraram em vigor prevendo que governos divulgassem, por 
exemplo, dados orçamentários e financeiros, bem como atos administrativos. Mas foi a Lei de Acesso à Informação (LAI), sancionada em novembro de 2011, que regulamentou em detalhes o acesso como regra e as condições do sigilo. A LAI instituiu o direito previsto na Constituição de que todos têm a prerrogativa de receber dos órgãos públicos, além de informações do seu interesse pessoal, também aquelas de interesse coletivo. Isto significa que a administração pública deve sistematizar a divulgação de suas ações e serviços em portais na internet, mas também deve estar preparada para receber demandas específicas.

A implementação das leis de transparência no Brasil visa estimular o desenvolvimento de uma cultura de acesso à informação no país após o governo militar, o qual deixou de herança uma cultura de sigilo nas instituições. Além de o acesso à informação estar inserido entre os direitos fundamentais, ele também é garantido pelo princípio da publicidade. A Constituição Federal prevê, em seu artigo 37, a publicidade como um dos princípios a serem obedecidos pela Administração Pública, ao lado de legalidade, impessoalidade, moralidade e eficiência.

Figura 1 - Evolução das leis de direito à informação no Brasil

\begin{tabular}{|c|c|c|}
\hline ANO & ATO JURÍDICO & EFEITO NA TRANSPARÊNCIA \\
\hline 1988 & ição Federal & $\begin{array}{l}\text { Art } 5 \text { XXXIII - todos têm direito a receber dos órgãos públicos } \\
\text { informações de seu interesse particular, ou de interesse coletivo ou } \\
\text { geral, que serão prestadas no prazo da lei, sob pena de } \\
\text { responsabilidade, ressalvadas aquelas cujo sigilo seja imprescindível } \\
\text { à segurança da sociedade e do Estado. }\end{array}$ \\
\hline 1988 & Cons & $\begin{array}{l}\text { Art } 216 \S 2^{\circ} \text { - Cabem à administração pública, na forma da lei, a } \\
\text { gestão da documentação governamental e as providências para } \\
\text { franquear sua consulta a quantos dela necessitem. }\end{array}$ \\
\hline 1988 & Constituição Federal & Art. 37 - Publicidade entre os princípios da Administração Pública. \\
\hline 1991 & $\begin{array}{l}\text { Lei no } 8.159 \text { - Política } \\
\text { nacional de arquivos } \\
\text { públicos e privados }\end{array}$ & $\begin{array}{l}\text { Art. } 7 \text { - Os arquivos públicos são os conjuntos de documentos } \\
\text { produzidos e recebidos, no exercício de suas atividades, por órgãos } \\
\text { públicos de âmbito federal, estadual, do Distrito Federal e municipal } \\
\text { em decorrência de suas funções administrativas, legislativas e } \\
\text { judiciárias. § 10 - São também públicos os conjuntos de documentos } \\
\text { produzidos e recebidos por instituições de caráter público, por } \\
\text { entidades privadas encarregadas da gestão de serviços públicos no } \\
\text { exercício de suas atividades. }\end{array}$ \\
\hline 1997 & $\begin{array}{l}\text { Lei no } 9.507 \text { - Habeas } \\
\text { Data }\end{array}$ & $\begin{array}{l}\text { Regula o direito de acesso a informações e disciplina o rito processual } \\
\text { do habeas data. }\end{array}$ \\
\hline 2000 & $\begin{array}{l}\text { Lei complementar n⿳⺈ } \\
101 \text { - Lei de } \\
\text { Responsabilidade }\end{array}$ & $\begin{array}{l}\text { Art. } 48 \text { - São instrumentos de transparência da gestão fiscal, aos } \\
\text { quais será dada ampla divulgação, inclusive em meios eletrônicos de } \\
\text { acesso público: os planos, orçamentos e leis de diretrizes } \\
\text { orçamentárias; as prestações de contas e o respectivo parecer prévio; } \\
\text { o Relatório Resumido da Execução Orçamentária e o Relatório de }\end{array}$ \\
\hline
\end{tabular}




\begin{tabular}{|c|c|c|}
\hline & Fiscal & Gestão Fiscal; e as versões simplificadas desses documentos. \\
\hline 2005 & $\begin{array}{l}\text { Lei no } 11.111 \text { - } \\
\text { regulamenta o acesso a } \\
\text { documentos públicos }\end{array}$ & Revogada pela Lei no 12.527 de 2011. \\
\hline 2009 & $\begin{array}{l}\text { Lei Complementar no } \\
131 \text { - altera a LC no } \\
101 \text { de } 2000\end{array}$ & $\begin{array}{l}\text { Determina a disponibilização, em tempo real, de informações } \\
\text { pormenorizadas sobre a execução orçamentária e financeira da } \\
\text { União, dos Estados, do Distrito Federal e dos Municípios. }\end{array}$ \\
\hline 2011 & $\begin{array}{l}\text { Lei no } 12.527 \text { - Lei de } \\
\text { Acesso à Informação } \\
\text { (LAI) }\end{array}$ & $\begin{array}{l}\text { Dispõe sobre os procedimentos a serem observados pela União, } \\
\text { Estados, Distrito Federal e Municípios, com o fim de garantir o acesso } \\
\text { a informações. }\end{array}$ \\
\hline 2016 & $\begin{array}{l}\text { Lei complementar no } \\
156 \text { - altera lei de } \\
\text { gestão fiscal no } 101\end{array}$ & $\begin{array}{l}\text { Art. } 27 \text { - } 0 \text { art. } 48 \text { da Lei Complementar no } 101 \text {, de } 4 \text { de maio de } 2000 \text {, } \\
\text { passa a vigorar com as seguintes alterações: } \\
\text { II - Liberação ao pleno conhecimento e acompanhamento da } \\
\text { sociedade, em tempo real, de informações pormenorizadas sobre a } \\
\text { execução orçamentária e financeira, em meios eletrônicos de acesso } \\
\text { público; } \\
\text { § 20 - A União, os Estados, o Distrito Federal e os Municípios } \\
\text { disponibilizarão suas informações e dados contábeis, orçamentários e } \\
\text { fiscais conforme periodicidade, formato e sistema estabelecidos pelo } \\
\text { órgão central de contabilidade da União, os quais deverão ser } \\
\text { divulgados em meio eletrônico de amplo acesso público. }\end{array}$ \\
\hline
\end{tabular}

Fonte: Brenol (2019); Brasil (1988; 1991; 1997; 2000; 2005; 2009; 2011; 2016).

A LAI concede o direito de acesso à informação a qualquer cidadão interessado e obriga os órgãos públicos integrantes da administração direta dos Poderes Executivo, Legislativo, incluindo as Cortes de Contas, Judiciário e do Ministério Público, as autarquias, as fundações públicas, as empresas públicas, as sociedades de economia mista e demais entidades controladas direta ou indiretamente pela União, Estados, Distrito Federal e Municípios a publicizar tais informações. As informações públicas digitais podem ser acessadas por meio da transparência ativa, em sites ou portais das instituições na internet, ou por meio de requisição via transparência passiva, via sistema de requisição no serviço de informação ao cidadão.

Esses dois mecanismos, garantidos pela LAI, são qualificadores da relação entre o Estado e os seus cidadãos, pois permitem livre acesso a informações de Estado, considerando que ao fim e ao cabo, o cidadão é o motivo de existir do Estado e, portanto, aqueles que gerem a coisa pública devem prestar contas. Entre os atores beneficiados pela lei em função da prática profissional estão os jornalistas. A transparência ativa (portais) e passiva (e-Sics) tornou-se uma forma através da qual os repórteres têm acesso a 
informações que constituem a apuração de suas pautas. Quando as informações públicas são disponibilizadas em formatos abertos à manipulação, elas possibilitam não apenas a leitura e análise, mas também a manipulação de dados em softwares de análise e cruzamento desses dados para gerar conhecimento. Em um estágio mais avançado, como previsto no artigo $8^{\circ}$ da lei, os dados abertos permitem conexões automatizadas por sistemas externos.

Assim, podemos inferir que: (1) as informações disponibilizados em portais são de domínio e propriedade pública e por meio delas o Estado devolve ao cidadão uma prestação de contas do governo; (2) os dados públicos quando digitalizados podem ser usados e apropriados por quaisquer atores sociais; (3) dados públicos abertos transferem poder a diferentes atores sociais que passam a exercer o seu papel na sociedade com finalidade de gerar conhecimento, comunicação, vigilância, prestação de serviço, pressão política e outros fins; (4) entre os atores que assumem para si o poder de vigilância e fiscalização estão os jornalistas na prática da apuração de temas de interesse público.

Portanto, neste artigo nos interessa em particular o papel social dos jornalistas, no exercício profissional de apuração, texto e reportagem, quando usa, ou seja, divulga dados públicos tratados pelos órgãos públicos ou terceiros, e/ou se apropria de dados, ou seja, manipula e transforma dados brutos em informações contextualizadas para formatar em notícia jornalística.

\section{Como o jornalismo usa os dados públicos}

Os primeiros anos da LAI impuseram aos jornalistas pautas de acompanhamento e adaptação dos órgãos públicos aos requisitos da LAI, em especial, na fiscalização da publicação dos portais de transparência e também na vigilância dos serviços de atendimento ao cidadão, como demonstram relatórios e pesquisas evidenciadas no levantamento bibliográfico. Os estudos mostram também que, ao longo dos anos, com o aprimoramento dos portais de transparência e a adaptação dos órgãos públicos aos requisitos da LAI, os jornalistas passaram a adotar o recurso na rotina de apuração.

0 primeiro ano de LAI foi objeto de um estudo desenvolvido pela Associação Brasileira de Jornalistas Investigativos (Abraji), publicado em 2013. Foram entrevistados 87 jornalistas de 27 cidades brasileiras em 14 estados entre 20 de fevereiro e 9 de abril de 2013. A pesquisa identificou o uso da lei pelo jornalismo como prática recorrente e mapeou os problemas enfrentados pelos jornalistas nas esferas federal, estadual e municipal. A 
maior parte dos problemas esteve relacionada aos poderes executivos. Uma das reclamações destacadas pela pesquisa versa justamente sobre os formatos dos arquivos disponibilizados. Neste sentido, os jornalistas cobraram maior empenho para a adoção de padrões de dados abertos pelos órgãos públicos. Um jornalista explicou a insatisfação: "órgãos estatais colocam dados à disposição, mas em formatos fechados, que não permitem ao cidadão reaproveitá-los, ou mesmo realizar as análises mais básicas" (ASSOCIAÇÃO BRASILEIRA DE JORNALISMO INVESTIGATIVO, 2013, p. 12).

A revisão bibliográfica foi realizada com base em pesquisa nas bases de dados dos periódicos da Coordenação de Aperfeiçoamento de Pessoal de Nível Superior (Capes, [2021]), na Biblioteca Digital Brasileira de Teses e Dissertações (BDTD, [2021]) e no repositório dos anais do Seminário em Pesquisa em Jornalismo Investigativo da Abraji ([2014]). Desde 2012, a LAI tem sido tema de artigos científicos e pesquisas acadêmicas que investigam os usos da lei pelos jornalistas (BOTTREL, 2016, 2018; DUTRA, 2015; FRARE, 2014; GENTILLI; SABINO, 2014; GERALDES; SOUSA, 2016; GERALDES; SOUSA; NEGRINI, 2017; GONÇALVES; STACCIARINI; NASCIMENTO, 2018; NASCIMENTO; RODRIGUES; KRAEMER, 2015). Os estudos desenvolveram análises de conteúdo em notícias que citavam a LAI textualmente ou que adotavam como método as entrevistas com profissionais que a utilizam.

Bottrel (2016) estudou a utilização da lei como efetiva implementação do direito de acesso. 0 método adotado para colher a amostra foi extrair notícias por meio do alerta por palavra-chave do mecanismo de busca do Google que abastece o site do Observatório de Gestão da Informação (OBGI) para, por meio de análise de conteúdo, identificar quais são os atores sociais que fazem uso da lei e com qual finalidade. Os achados indicaram uma participação maior dos órgãos públicos como fonte, com 52,6\% das notificações, e a sociedade civil com $45,6 \%$. Outro achado importante diz respeito ao peso que a imprensa obteve no resultado da amostra que incluiu sites de empresas, blogs e outros canais.

Sobre a atuação da Imprensa, um primeiro ponto que ficou evidente foi a utilização da LAI como instrumento de trabalho, buscando dados para basear a redação de matérias jornalísticas, além da fiscalização das ações públicas, especialmente os veículos de comunicação Folha de SP, Estado de SP e A Cidade, apontando uma possível absorção do uso do acesso à informação na sua rotina de trabalho. (BOTTREL, 2016, p. 80). 
Geraldes e Sousa (2016) também apontam mudanças nas rotinas de trabalho nas redações a partir de um artigo teórico com base nas premissas de newsmaking. Os achados indicam uma redução de dependência da redação nas assessorias de imprensa, mas um dilema em relação à imediaticidade como característica jornalística. 0 tempo de resposta aos pedidos de transparência passiva, associado ao tempo maior da produção da notícia com base em dados brutos disponibilizados pelos órgãos governamentais, tende a afrontar os processos produtivos imediatistas. Portanto, o estudo aponta que essas circunstâncias podem fazer as redações considerarem "a investigação uma prioridade e o planejamento das edições para além de matérias apressadas e priorize textos acurados e bem apurados" (GERALDES; SOUSA, 2016, p. 17). Como apontamento final, os autores indicam a necessidade de o jornalista estar apto a compreender e explicar os índices, dados e indicadores sobre o Estado brasileiro.

Em outro estudo, realizado por Nascimento, Rodrigues e Kraemer (2015), também surge um resultado positivo quanto à adoção de informações pedidas via LAI em reportagens. 0 trabalho focou nos temas mais abordados pela imprensa nos dois primeiros anos de vigência da lei. Os autores analisaram 96 reportagens que publicaram informações obtidas por meio da LAI nos jornais Folha de S. Paulo, Estado de São Paulo e o 0 Globo e identificaram que ética pública e serviços públicos foram priorizados em detrimento a temas como a ditadura militar. 0 estudo mostrou que 65 repórteres assinaram as reportagens, o que indica o uso da LAI na rotina jornalística.

Dutra e Paulino (2016) analisam a cobertura dos mesmos veículos impressos de referência sobre a LAI em 2012 e 2013. Foram consideradas 314 matérias jornalísticas e 101 textos diversos (editoriais, entrevistas, artigos de opinião etc.). 0 jornal Folha de $\mathrm{S}$. Paulo liderou as publicações sobre o tema seguido por O Estado de São Paulo e pelo O Globo, sendo a editoria de Política a que fez maior uso da LAI para reportagens. Também foi encontrado que a maior parte das reportagens que citam a lei versam sobre questões do Poder Executivo federal.

Dutra (2015) também investigou os usos que os jornalistas fazem da LAI. A autora identificou o uso mais frequente do recurso da lei em pautas extensas e em temas relativos à execução de gastos da administração pública, andamento de políticas públicas do governo federal e documentos da ditadura militar. A questão do tempo de produção foi abordada nas entrevistas: os repórteres explicaram que não podem depender do e-SIC para notícias do dia a dia, só em casos de uma pauta com tempo maior de produção. Os jornalistas ainda 
destacaram como positiva a redução da dependência das assessorias de imprensa, em especial por não precisarem justificar o motivo do pedido das informações como tinham de fazer anteriormente, mas afirmam que nas notícias factuais ainda são dependentes das assessorias.

Um estudo desenvolvido com os dados de requisições de informações feitas por jornalistas por meio da LAI em 2017 evidenciou que há um uso efetivo do recurso no país. 0 estudo levantou todos os pedidos feitos por jornalistas identificados e constatou 3.386 pedidos feitos por 856 jornalistas, sendo que a maior parte requisitou apenas uma informação, mas há um grupo recorrente que faz uso do recurso com bastante frequência (GONÇALVES; STACCIARINI; NASCIMENTO, 2018).

Desde maio de 2012, quando a LAI entrou em vigor, até 31 de dezembro de 2017, 3.307 jornalistas assim registrados no sistema eletrônico e-Sic apresentaram pedidos de informação. Esse grupo formulou um total de 16.616 pedidos, o que dá uma média de cinco pedidos por jornalista no período. Considerando todos os pedidos de cidadãos, o e-Sic contabiliza 567.668 de requisições de informação de maio de 2012 ao final de 2017. (GONÇALVES; STACCIARINI; NASCIMENTO, 2018, p. 131).

O estudo explica que apesar de haver pouco mais de três mil jornalistas registrados no e-Sic do Executivo federal, pode haver mais pedidos feitos por jornalistas porque a LAI não obriga a identificação da profissão, tendo em vista que qualquer cidadão tem o direito de requerer informações públicas de seu interesse. No estudo, os autores analisaram apenas os pedidos de transparência passiva, ou seja, que demandam uma solicitação expressa porque não estão disponíveis em portais.

Outra questão relevante a ser considerada é que a LAI prevê o acesso em transparência passiva e ativa. Nos casos levantados acima, os estudos focaram nos pedidos por meio do serviço de informação ao cidadão, ou seja, pedidos realizados quando os dados necessários para a pauta não estão disponibilizados de forma ativa em sites. Nesse sentido, é possível que a LAI tenha surtido um efeito ainda maior no uso e apropriação de dados públicos por jornalistas em suas pautas, porém não necessariamente suscetível de mapeamento e rastreabilidade, pois os autores não necessitam citar a LAI para se referir a dados disponíveis a priori.

Portanto, deste breve levantamento de estudos no campo de pesquisa em jornalismo podemos inferir que: (1) os jornalistas adotam os recursos normativos para acessar dados 
públicos; (2) de 2012 a 2017 houve um incremento no uso desse recurso pelos jornalistas, evidenciado pelo aumento de pedidos, consultas e publicações, nos quais a LAI passa de objeto da reportagem a fonte jornalística; (3) o uso destes recursos digitais está associado pelos pesquisadores a reportagens de investigação, considerando que o tempo da notícia factual não permite aprofundar a análise de dados; (4) a relação entre jornalistas de redação e de assessoria de imprensa sofre alterações, reduzindo a dependência e recriando formas de interação, que podem se tornar objeto de estudo do campo.

\section{Discussão}

Como os estudos reunidos neste artigo mostram, os jornalistas entendem a LAI e outras leis de transparência como um instrumento de trabalho e fazem uso deste recurso de acesso a dados públicos para produção de reportagens sobre temas públicos, prática intensificada a partir dos anos 2010. Para autores da democracia digital (BARROS; SAMPAIO, 2017; DAHLBERG, 2011; FENSTER, 2015; GOMES, 2007; MARGETTS, 2011; SAMPAIO, 2010) e da comunicação pública (ESTEVES, 2007; WEBER, 2017), os jornalistas, ao se apropriarem destes dados e transformá-los em publicações, tornam-se atores sociais que entram em disputa com outros atores em redes de comunicação pública (WEBER, 2007, 2017) para serem reconhecidos como mediadores e tradutores de informações públicas de interesse público em linguagem universal.

O lócus da relevância do ator jornalismo não está na disseminação e distribuição visto que há uma multiplicidade de canais e atores sociais em disputa na interlocução - mas na qualidade da abordagem do tema para o debate público. Essa migração da escassez dos meios para a abundância informativa determina uma revisão nas dinâmicas e processos de comunicação, inclusive no valor do imediatismo para a qualidade da notícia.

A qualidade da informação produzida por jornais de legado como os citados nos estudos da revisão bibliográfica tende a estar no acionamento do pluralismo de vozes para o debate público a partir das técnicas de apuração e valores jornalísticos. Essa é a chave para diferenciar o jornalismo profissional da mídia das fontes (SANT'ANNA, 2005). A mídia das fontes constitui canais de produção e distribuição de conteúdo a partir de estratégias de marketing e relações públicas de organizações públicas e privadas forjando um novo modelo comunicacional adotado não apenas por movimentos sociais e políticos, mas também por segmentos sociais de alto poder econômico e político como empresários, juristas, militares, 
médicos e outros grupos sociais influentes. Esse contexto propiciou ao profissional jornalista um alargamento do campo de atuação profissional, visto que a mídia de fonte é um espaço potencialmente ocupado por jornalistas profissionais, porém atendendo interesses específicos, não necessariamente coincidindo com o norte do interesse público.

De fato, não só no Brasil, a internet oportunizou a fontes criarem canais para influenciar a agenda da imprensa de legado e para elas mesmas assumirem o papel de difusor de informações, antes atribuído a grandes grupos detentores dos meios de produção e transmissão de informações. A consecução de debate público sobre temas de interesse público permite que a relevância de um tema seja apreendida e contextualizada de modo permanente, recorrente e fluído em oposição aos interesses puramente privados e aos desvios éticos dos homens públicos. 0 debate, portanto, é fundamental para as democracias e muitas vezes é desafiado por campanhas publicitárias, propagandas e pelas chamadas fake news, circulando predominantemente em sites de redes sociais e em aplicações de mensagens instantâneas.

Desta forma, o movimento permanente de debate de interesse público "seria o procedimento necessário para a compreensão e avaliação da qualidade das democracias" (WEBER, 2017, p. 25). Em governos totalitários, nos quais há controle da informação de Estado e pelo Estado, não há comunicação pública, se sobressai a propaganda e a divulgação do governo em busca de autolegitimação. A comunicação pública, por vezes confundida com a comunicação governamental, passa pelo governo (e pode ter origem em dados governamentais), mas reside no debate de temas de interesse público afetando atores públicos e privados como a imprensa tradicional e as mídias das fontes.

Portanto, Weber defende a comunicação pública como debate público "acionado por temas de interesse público provocados a partir de poderes da República, de instituições, sistemas de mídia ou redes de comunicação capazes de gerar disputa de opiniões, ações coletivas, associações e mobilizações consequentes ou não" (WEBER, 2017, p. 29). No mesmo sentido, Weber e Coelho (2011) acreditam que o caráter mediador está na prerrogativa da publicidade valorada pela informação em circulação, pois

tornar público é fonte de poder; selecionar o que será visível, reconhecível implica considerar não apenas critérios, como também uma questão ética, do dever ser. Essa dimensão pública é, portanto, essencial ao jornalismo. (WEBER; PFEIFER; COELHO, 2011, p. 62). 
As autoras ainda diferenciam a dimensão pública do jornalismo em relação às instituições e empresas privadas que produzem informações e limitam o alcance do público quando direcionados a uma fração de mercado ou a um público segmentado. Muitas vezes, as assessorias de imprensa governamentais produzem informações segmentadas, sem apontar o contraditório ou vigiar o poder.

Nesse mesmo sentido, Sartor (2016) sustenta que o jornalismo é um dos atores mais importantes dos processos de comunicação pública. Os temas de interesse público mostramse aptos a agregar e pautar diferentes atores em redes de comunicação pública. Desta feita, o interesse público como um conceito amplo entra em disputa discursiva na rede e, quando adotado pelo discurso jornalístico, pode estar ora associado a valores democráticos da cidadania ora a questões mercadológicas de autolegitimação (SARTOR, 2016).

Percebe-se no jornalismo, na perspectiva associada a valores de cidadania, a apropriação de dados públicos, com técnicas de jornalismo guiado por dados (JGD) ou de jornalismo investigativo. A técnica de apuração requer o tratamento das informações de forma o mais objetiva possível, para que o resultado apresente documentos, números, descrições sistemáticas que tornem a reportagem verificável. Desta forma, oferece ao leitor a possibilidade de percorrer a trajetória do repórter na construção da reportagem para que possa ele mesmo interpretá-la, salvaguardando "uma aura de objetividade" na identidade jornalística (TRÄSEL, 2018, p. 11).

Ao estruturar um ciclo de governo aberto ideal, Safarov, Meijer e Grimmelikhuijsen (2017) localizam o jornalista como usuário de dados digitais com apropriação direta, ao lado de atores como desenvolvedores ou programadores, pesquisadores, empresas, organizações não-governamentais. Os autores do esquema teórico (SAFAROV; MEIJER; GRIMMELIKHUIJSEN, 2017) relacionam o cidadão na coletividade como usuário indireto dos dados abertos. Para que esse uso seja possível, os autores apontam (1) as condições técnicas (disponibilidade dos dados, qualidade do arquivo) e sociais (legislação, políticas públicas); (2) os tipos analíticos (pesquisa, tomada de decisão) e sintéticos (inovação, serviço, hackatons); (3) efeitos sociais (valores sociais, serviço público) desenvolvimento econômico (novos negócios e prestações de serviço) e boa governança (transparência e accountability). Para os autores, o tipo analítico faz uso de dados visando o entendimento e a explicação de características do mundo, enquanto o tipo sintético contribui para o desenvolvimento de ferramentas mais funcionais. 0 artigo analisou 101 pesquisas sobre governo aberto e, entre os usos que os jornalistas fazem dos dados, se destacam trabalhos de cunho analítico. 
Os jornalistas são um grupo de usuários altamente envolvido na utilização do OGD em suas atividades diárias para realizar estudos e escrever artigos de jornal, incluindo a visualização de dados públicos. Os jornalistas, por exemplo, podem integrar vários conjuntos de dados para trazer novas percepções que os indivíduos podem não ser capazes. Além disso, juntamente com a abertura de dados públicos relevantes, a política do governo deve esforçar-se para aumentar a motivação dos jornalistas de dados e seus programas comunitários de implementação, apoio de ONGs e fundos direcionados para resolver problemas sociais, particularmente corrupção e uso indevido de recursos públicos. (SAFAROV; MEIJER; GRIMMELIKHUIJSEN, 2017, p. 18).

Nesse mesmo sentido, outros estudos destacam os trabalhos do jornalismo para traduzir e comunicar os dados com características de universalidade (BRENOL, 2019; DAHLBERG, 2011; MARGETTS, 2011) e impacto social para o debate público (BRENOL, 2019). Para Margetts (2011), é esperado do cidadão confiar a outras partes a análise dos dados disponíveis em grande quantidade, o que um cidadão sozinho não poderia dar conta por tempo e por recursos ou competências específicas. A transparência digital envolve grandes quantidades de dados ou a tradução de processos governamentais em códigos de programação, implicando em delegação de confiança. A autora atribui ao jornalismo, mais especificamente às organizações jornalísticas, uma destas forças capazes de traduzir a grande quantidade de dados. A autora exemplifica com um caso britânico de 2009, quando o parlamento inglês foi obrigado a divulgar as despesas dos representantes e o jornal The Telegraph criou uma ferramenta interativa para que o cidadão pudesse acessar as informações. Esse recurso foi possível porque o jornal tinha uma equipe de jornalistas trabalharam na leitura e análise de milhares de documentos para moldar um site interativo e disponibilizar para a população. "A confiança se transfere de instituições tecnologicamente e estatisticamente capacitadas - e com recursos adequados - para organizações e indivíduos com capacidade de extrair as vantagens que a internet pode fornecer" (MARGETTS, 2011, p. 520). Para Margetts (2011), o lugar do jornalismo está em se apropriar de dados e desenvolver as ferramentas de acesso para o público, mas há situações em que o jornalismo estará no lugar de usuário de ferramentas ou leituras produzidas por terceiros - como instituições de ensino, organizações não-governamentais, sociedade civil organizada, partidos políticos, os próprios governos e outros atores e redes de comunicação. Nesses casos, o papel do jornalismo estará em reportar as informações tecnologicamente analisadas e programadas por terceiros. 
Brenol (2019), ao mapear uma rede de jornalistas praticantes deste tipo de reportagem, identificou que o grupo de 29 jornalistas acionados se percebe como fiscal do poder quando pratica reportagens a partir da manipulação de informações públicas. 0 estudo mostrou que essa prática evidencia com mais frequência trabalhos com os temas políticos como corrupção, eleições, finanças públicas, confirmando um tipo analítico de uso dos dados públicos. Interessante observar que o grupo recomendou trabalhos realizados nos anos 1990 como referência em jornalismo de dados públicos. Na época, os repórteres acessaram as informações nos computadores dos próprios órgãos públicos como o Tribunal Superior Eleitoral e a Assembleia Legislativa do Rio de Janeiro. Ou seja, a investigação jornalística possuía o consentimento dos setores de assessoria de imprensa e de relações públicas. Foi o caso da reportagem da Folha de S. Paulo Deputados empregam 315 parentes, publicada em 1999 e com autoria de Lucio Vaz (1999), que alimentou o debate público sobre o nepotismo no poder público e teve como consequência do debate a publicação da Súmula Vinculante número 13 pelo Supremo Tribunal Federal e um decreto executivo para coibir a contratação de parentes. 0 jornalismo cumpriu, neste caso, por meio da publicização de dados públicos, o papel social de mediar o debate público e provocar os poderes à ação.

Outro exemplo, pós-LAI, de uso de dados públicos digitais para qualificar o debate público esteve em reportagem do jornal 0 Globo que fez uso de dados da Força Aérea Brasileira (FAB) para gerar a discussão sobre as prioridades do transporte aéreo (SASSINE, 2016). Os dados mostram que as aeronaves vinham sendo usadas mais para transporte de políticos do que para salvar vidas. A Aeronáutica não é obrigada por lei a transportar órgãos para transplante, mas a reportagem apurou que existe um termo de cooperação envolvendo o Ministério da Saúde, as empresas de aviação comercial e a FAB. Quando não há rotas comerciais ou existe uma urgência, a FAB é acionada. 0 debate público levantado pela reportagem versa sobre o uso - previsto em lei - do mesmo transporte para autoridades, enquanto órgãos humanos vitais não chegam em tempo hábil ao destino. A publicação impactou em um decreto presidencial assinado pelo presidente Michel Temer para que uma aeronave ficasse sempre à disposição para o transporte de órgãos para transplante. Brenol (2019) afirma assim que a qualidade do debate público é evidenciada nesta mediação jornalística quando "1) aciona atores políticos, sociais e civis; 2) impacta na tomada de decisão ou acarreta atos políticos por atores relevantes e 3) permite o aprofundamento de temas de interesse público por um período de tempo. (BRENOL, 2019, p. 190)”. 


\section{Conclusão}

O objetivo traçado para este artigo foi, a partir da revisão de estudos sobre transparência pública e jornalismo, situar o jornalismo na democracia digital. Concluímos, a partir do levantamento teórico acerca do jornalismo, que os estudos evidenciam, no campo de pesquisa não apenas do jornalismo, mas também da comunicação e das ciências sociais, o reconhecimento do uso que o jornalista como profissional e o jornalismo como campo fazem de dados públicos orientados por valores de interesse público, usualmente utilizando dados de forma analítica e com efeito social visando a prestação de serviço para a cidadania.

Assim, fica evidenciado que quando o Estado efetivamente devolve ao cidadão uma prestação de contas em formato de dados nos moldes previstos em lei, o governo transfere poder a diferentes atores sociais que tornam-se aptos a gerar conhecimentos novos, criar formatos interessantes de comunicação, mas também desenvolver estratégias de vigilância ou mesmo inovação em prestação de serviço.

Os jornalistas fazem uso efetivo deste poder delegado quando assumem para si a fiscalização de atos e ações governamentais em pautas de interesse público. 0 levantamento destacado neste estudo, no entanto, indica que apesar do incremento nessa prática, o principal instrumento de acesso a informações tem de ser acionado por meio de requisição aos órgãos responsáveis, nos prazos da lei, ou seja, com o uso dos recursos de transparência passiva. Isso significa que os dados disponibilizados a priori nos sites de transparência não atendem às demandas de pautas jornalísticas, em especial de cunho investigativo.

E, apesar dos estudos reforçarem, por meio dessa prática, o papel social do jornalista de qualificar o debate público de temáticas de interesse coletivo em redes de comunicação pública cada vez mais entranhadas em ambientes de abundância informativa, é importante ressaltar o contexto. Se as normas de transparência pública digital se consolidaram em uma tendência mundial de abertura de governos até meados dos anos 2010, recentemente tem se observado acontecimentos no sentido contrário. De 2012 a 2020, o contexto político nacional e internacional tem provocado pressões e constrangimentos, bem como ações governamentais de limitações à transparência pública que podem interferir diretamente no acesso a informações públicas por parte dos jornalistas.

A digitalização dos governos para atribuir maior transparência à gestão é imprescindível para que a democracia se consolide como regime, pois a opacidade do poder é a negação da democracia (BOBBIO, 2015). 0 jornalismo na democracia digital se posiciona 
como um dos atores com habilidades e competências para fazer as informações públicas disponibilizadas por meios de transparência digital ganharem visibilidade, alcance e consequência na qualificação do debate público. Justamente nessa condição, o papel do jornalismo se torna cada vez mais relevante no sentido de vigilância governamental, inclusive para garantir que não haja retrocesso no processo de transparência e nas políticas de governo aberto.

\section{Referências}

ASSOCIAÇÃO BRASILEIRA DE JORNALISMO INVESTIGATIVO. Relatório de desempenho da lei de acesso a informações públicas: avaliação, sugestão e críticas do uso da lei por jornalistas. São Paulo: Abraji, 2013.

ASSOCIAÇÃO BRASILEIRA DE JORNALISMO INVESTIGATIVO. Seminários de Pesquisas em Jornalismo Investigativo. Anais [...]. São Paulo: Abraji, 2014. Disponível em: http://www.abraji.org.br/seminario/anais.html.

BOBBIO, Norberto. Democracia e segredo. São Paulo; Editora Unesp, 2015.

BARROS, Samuel Anderson Rocha; SAMPAIO, Rafael Cardoso. A confiança para a manutenção de uma inovação democrática: o caso do orçamento participativo digital de Belo Horizonte. Cadernos Gestão Pública e Cidadania, [s.l.], v. 22, n. 72, p. 151-172, maio/ago. 2017.

BOTTREL, Rachel do Monte. Uma análise dos usos da lei de acesso à informação no Brasil em notícias do período de 2013 a 2015. Dissertação (Mestrado em Ciência da Informação) - Universidade Federal do Rio de Janeiro, Rio de Janeiro, 2016.

BOTTREL, Rachel do Monte. A Contribuição do Acesso à Informação Pública para a Comunicação Pública no Brasil. Comunicação Pública, [s.l.], v. 13, n. 24, 2018.

BRASIL. [Constituição (1988)]. Constituição da República Federativa do Brasil de 1988. Brasília, DF; Presidência da República, 1988.

BRASIL. Lei no 8.159, de 8 de janeiro de 1991. Política nacional de arquivos públicos e privados. Diário Oficial da União, Brasília, DF, p. 455, 9 jan. 1991. Retificado em 28 jan. 1991.

BRASIL. Lei no 9.507, de 12 de novembro de 1997. Regula o direito de acesso a informações e disciplina o rito processual do habeas data. Diário Oficial da União, p. 26025, 13 nov. 1997. 
BRASIL. Lei complementar no 101, de 4 de maio de 2000. Estabelece normas de finanças públicas voltadas para a responsabilidade na gestão fiscal e dá outras providências. Diário Oficial da União, p. 1, 5 maio 2000.

BRASIL. Lei no 11.111, de 5 de maio de 2005. Regulamenta a parte final do disposto no inciso XXXIII do caput do art. 50 da Constituição Federal e dá outras providências. Diário Oficial da União, Brasília, DF, 6 maio 2005.

BRASIL. Lei complementar no 131, de 27 de maio de 2009. Acrescenta dispositivos à Lei Complementar no 101, de 4 de maio de 2000, que estabelece normas de finanças públicas voltadas para a responsabilidade na gestão fiscal e dá outras providências, Diário Oficial da União, p. 2, 27 de maio 2009.

BRASIL. Lei no 12.527, de 18 de novembro de 2011. Regula o acesso a informações previsto no inciso XXXIII do art. 5ำ, no inciso II do § $3^{\circ}$ do art. 37... Diário Oficial da União, Brasília, DF, 18 nov. 2011. Edição extra.

BRASIL. Lei complementar no 156, de 28 de dezembro de 2016. Estabelece o Plano de Auxílio aos Estados e ao Distrito Federal e medidas de estímulo ao reequilíbrio fiscal; altera a lei de gestão fiscal no 101. Diário Oficial da União, p. 1, 28 dez. 2016.

BRENOL, Marlise Viegas. Transparência digital e jornalismo: modalidades comunicativas com uso de dados públicos. Tese (Doutorado em Comunicação e Informação) - Universidade Federal do Rio Grande do Sul, Porto Alegre, 2019.

COORDENAÇÃO DE APERFEIÇOAMENTO DE PESSOAL DE NÍVEL SUPERIOR. Portal de Periódicos da Capes. Brasília: Capes, [2021].

DAHLBERG, Lincoln. Re-constructing digital democracy: An outline of four 'positions. New Media \& Society, [s.l.], v. 13, n. 6, p. 855-872, feb. 2011.

DUTRA, Luma Poletti. Direito à informação em pauta: os usos da lei de acesso por jornalistas. 2015. Dissertação (Mestrado em Comunicação) - Universidade de Brasília, Brasília, 2015.

DUTRA, Luma Poletti; PAULINO, Fernando Oliveira. Direito à informação em pauta: lei de acesso e jornais impressos. Revista Latinoamericana de Ciencias de la Comunicación, [s.l.], v. 11, n. 21, p. 184-193, 2015.

ESTEVES, João Pissarra. Internet e Democracia: Estado e Sociedade Civil perante os novos desafios da comunicação política. Media \& Jornalismo, Lisboa, v. 10, p. 33-42, 2007a.

ESTEVES, João Pissarra. Internet e comunicação política: um novo desafio à democracia. Intexto, Porto Alegre, n. 17, p. 1-12, 2007 b.

FENSTER, Mark. Transparency in search of a theory. European Journal of Social Theory, [s.l.], v. 18, n. 2, p. 150-167, apr. 2015. 
FRARE, Marcilene Aparecida Mangini. A amplitude da lei de acesso à informação (LAI) analisada sob os interesses do Estadão. 2014. Dissertação (Mestrado em Comunicação) Universidade Paulista, São Paulo, 2014.

GENTILLI, Victor; SABINO, Ana Carolina de Angeli. A cobertura jornalística no segundo ano da Lei de Acesso à Informação. In: ENCONTRO NACIONAL DE PESQUISADORES EM JORNALISMO, 12., 2014, Santa Cruz do Sul. Anais... [...]. Santa Cruz do Sul: Universidade de Santa Cruz do Sul, 2014.

GERALDES; Elen; SOUSA, Janara. 0 impacto da lei de acesso à informação nas rotinas produtivas do jornalismo brasileiro. Revista Eptic, [s.I.], v. 18, n. 3, p. 7-18, 2016.

GERALDES; Elen; SOUSA, Janara; NEGRINI, Vanessa. 0 impacto da lei de acesso à informação nas relações entre os jornalistas e as assessorias de imprensa governamentais. $I n$ : COMPOLÍTICA - Associação Brasileira de Pesquisadores em Comunicação e Política, 7., 2017, Porto Alegre. Anais... [...]. Rio de Janeiro: COMPOLÍTICA, 2017.

GOMES, Wilson. Democracia digital: que democracia. In: II ENCONTRO DA ASSOCIAÇÃO NACIONAL DE PESQUISADORES EM COMUNICAÇÃO E POLÍTICA, 5., Belo Horizonte. Anais [...]. UFMG: Belo Horizonte, 2007.

GONÇALVES, Francisco Eduardo; STACCIARINI, Isa Coelho; NASCIMENTO, Solano. O uso da LAI por jornalistas: uma análise de requerentes, pedidos e respostas. Estudos em Jornalismo e Mídia, Florianópolis, v. 15, n. 2, p. 130-140, 2018.

INSTITUTO BRASILEIRO DE INFORMAÇÃO EM CIÊNCIA E TECNOLOGIA. Biblioteca Digital Brasileira de Teses e Dissertações. Brasília: Ibct, [2021]. Disponível em: http://bdtd.ibict.br/vufind/.

MARGETTS, Helen. The internet and transparency. The Political Quarterly, [s.I], v. 82, n. 4, p. 518-521, 2011.

MENDEL, Toby. Liberdade de informação: um estudo de direito comparado. Brasília: UNESCO, 2009.

NASCIMENTO, Solano; RODRIGUES, Georgete Medleg; KRAEMER, Luciana. A utilização da Lei de Acesso à Informação pela imprensa: análise dos jornais Folha de S. Paulo, O Estado de S. Paulo e 0 Globo. Rumores, São Paulo, v. 9, n. 18, p. 225-248, jul./dez. 2015.

ORGANIZAÇÃO DAS NAÇÕES UNIDAS. Declaração Universal dos Direitos Humanos. Rio de Janeiro: UNIC, 2009.

SAFAROV. Igbal; MEIJER, Albert; GRIMMELIKHUIJSEN, Stephan. Utilization of open government data: A systematic literature review of types, conditions, effects and users. Information Polity, [s.I]. v. 22, n. 1, p. 1-24, 2017.

SAMPAIO, Rafael Cardoso. Participação política e os potenciais democráticos na internet. Revista Debates, Porto Alegre, v. 4, n. 1, p. 29-53, jan./jun. 2010. 
SANT'ANNA, Francisco. Mídia das fontes: o difusor do jornalismo corporativo. Brasília: Casa das Musas, 2005.

SARTOR, Basilio Alberto. A noção de interesse público no jornalismo. Tese (Doutorado em Comunicação e Informação) - Universidade Federal do Rio Grande do Sul, 2016.

SASSINE, Vinicius. Sistema de transplantes no Brasil sofre com falta de transporte aéreo. 0 Globo, Rio de Janeiro, 5 jun. 2016.

SILVA, Silvado Pereira da; SAMPAIO, Rafael Cardoso; BRAGATO, Rachel Callai. Democracia digital, comunicação política e redes: teoria e prática. Rio de Janeiro: Folio Digital - Letra e Imagem, 2016.

TRÄSEL, Marcelo. Hacks and hackers: the ethos and beliefs of a group of Data-Driven Journalism professionals in Brazil. Revista Famecos, Porto Alegre, v. 25, n. 1, 2018.

VAZ, Lucio. Deputados empregam 315 parentes. Folha de S. Paulo, São Paulo, 17 out. 1999.

WEBER, Maria Helena. Na comunicação pública, a captura do voto. Logos, v. 14, n. 2, p. 2142, 2007.

WEBER, Maria Helena. Nas redes de comunicação pública, as disputas possíveis de poder e visibilidade. Comunicação Pública e Política--pesquisa e práticas. Florianópolis: Insular, p. 23-56, 2017.

WEBER, Maria Helena; COELHO, Marja Pfeifer. Entre jornalismos e poderes. SILVA, G.; KUNSCH, D.; BERGER, C. p. 51-78, 2011.

\title{
Journalism and public data transparency
}

\begin{abstract}
The purpose of this article is to situate journalism in digital democracy. As methodology, we chose systematic research review and discussion. We propose to approach the issue through: evolution of the normativity of digital public transparency in Brazil; use and appropriation of information access in journalistic practice, considering digital democracy and public communication concepts. As a result, we evidenced a significant set of studies that show that journalism has adopted, in particular, passive transparency instruments to access public data and that this practice has been intensified in Brasil since the approval of Information Act (LAI) in 2011.
\end{abstract}

\section{Keywords}

Freedom of Information Act, Digital journalism. Public transparency. Public data. Digital democracy. Information access law. 


\section{Autoria para correspondência}

Marlise Viegas Brenol

marlisebrenol@gmail.com

\section{Como citar}

BRENOL, Marlise Viegas. Jornalismo e transparência pública digital: aliados pela qualidade do debate público. Intexto, Porto Alegre, n. 52, e-94992, jan./dez. 2021. DOI: http://dx.doi.org/10.19132/18078583202152.94992

Recebido em 30/07/2019

Aceito em 11/01/2021 